Tópico de Interesse Geral

\title{
Qualidade do leite: utopia sem um programa sério de monitoramento da ocorrência de mastite bovina ${ }^{1}$
}

\author{
Helio Langoni ${ }^{2}$
}

\begin{abstract}
Langoni H. 2013. [Milk quality: an utopia without a rigorous monitoring program for bovine mastitis control.] Qualidade do leite: Utopia sem um programa sério de monitoramento da ocorrência de mastite bovina. Pesquisa Veterinária Brasileira 33(5):620-626. Departamento de Higiene Veterinária e Saúde Pública, Faculdade de Medicina Veterinária e Zootecnia, Universidade Estadual Paulista "Júlio de Mesquita Filho", Distrito de Rubião Junior s/n, Botucatu, SP 18618-970, Brazil. E-mail: hlangoni@fmvz.unesp.br

Bovine mastitis is still a costly issue in dairy farms, besides public health aspects considering the pathogen transmission to humans. Its multiple etiology with a high number of pathogens involved, demands a rigorous control program for monitoring and milk quality control, based on diagnostic actions and epidemiological vigilance regarding parameters which indirectly are associated with the occurrence of mastitis in dairy herds, as the California Mastitis Test (CMT) and Somatic Cell Count (SCC/mL of milk), of individual milk samples obtained from each cow, and from bulk tank which also allows the Total Bacteria Count (TBC), usually related to the incidence of mastitis, especially in subclinical cases. It is important to reinforce the microbiological milk exam, also to stress the importance of the milking process as a critical point, and to determine risk factors for mastitis. Based on these aspects, this review is presented with the aim to obtain high quality milk products, compromising the personal enrolled in milk production to be conscious that milk quality depends on all, inclusive the consumers which are the final element in the milk production chain.
\end{abstract}

INDEX TERMS: Mastitis, milk quality, control.

RESUMO.- As mastites continuam sendo um dos principais problemas a onerar a pecuária leiteira, além dos aspectos de saúde pública, considerando-se a veiculação de patógenos causadores de doença em humanos. Sua múltipla etiologia, com o envolvimento de inúmeros patógenos, requer um programa de controle rigoroso para o seu monitoramento e controle de qualidade do leite, pautado em ações diagnósticas e de vigilância epidemiológica com relação a parâmetros que indiretamente associam-se à ocorrência de mastites nos rebanhos, como California Mastitis Test (CMT) e Contagem de Células Somáticas (CCS/mL de leite), de amostras de leite individuais composta de cada vaca, bem como do tanque de expansão, o que permite ainda o monitoramento da Contagem Bacteriana Total (CBT), que tende a se relacionar com a ocorrência de mastites,

\footnotetext{
${ }^{1}$ Recebido em 4 de dezembro de 2012.

Aceito para publicação em 1 de março de 2012.

${ }^{2}$ Departamento de Higiene Veterinária e Saúde Pública, Faculdade de Medicina Veterinária e Zootecnia, Universidade Estadual Paulista "Júlio de Mesquita Filho" (Unesp), Distrito de Rubião Junior s/n, Botucatu, SP 18618-970, Brasil. E-mail: hlangoni@fmvz.unesp.br
}

principalmente subclínicas. Destacam-se ainda aspectos de exame microbiológico do leite e da importância da ordenha como ponto crucial nas mastites, enfatizando aspectos relevantes do processo de ordenha com fatores de risco para a ocorrência das mastites. Baseando-se nestes aspectos, apresenta-se esta revisão, acreditando-se na possibilidade de obtenção de produtos lácteos de melhor qualidade, com o comprometimento de todos os envolvidos na cadeia produtiva do leite, conscientes de que a qualidade do leite depende de todos, valendo-se também os consumidores, que são os elementos finais da cadeia produtiva do leite.

TERMOS DE INDEXAÇÃO: Mastite, qualidade do leite, monitoramento.

\section{INTRODUÇÃO}

Há motivos mais que suficientes para se preocupar com a ocorrência de mastites em propriedades leiteiras. Primeiro porque é a doença mais frequente nos animais destinados a produção leiteira e segundo porque impacta negativamente a pecuária leiteira. Devem ser ressaltados os aspectos relacionados à diminuição da produção (Lescourret \& 
Coulon 1994, Domingues et al. 1998), menor rendimento na produção de derivados lácteos, diminuição do tempo de prateleira do produto, custos com medicamentos, honorários profissionais, descarte do leite durante o tratamento e período de carência, possibilidade de perda de tetos e muitas vezes da vaca devido a septicemia, e ainda pelo descarte prematuro de animais (Fetrow et al. 1991, Miller et al. 1993). Além de todos esses pontos levantados, tem que se considerar os aspectos de saúde pública, pois muitos patógenos causadores de mastites oferecem riscos ao consumidor de leite e derivados (Vasconcelos \& Ito 2011), ou de produtos metabólicos como principalmente as enterotoxinas (Cerqueira \& Leite 1995, De Buyser et al. 2001, Fagundes \& Oliveira 2004, Oliver et al. 2005, Guimarães \& Langoni 2009).

Neste contexto a implantação de um programa para o controle de mastites é de extrema importância, onde o veterinário envolvido com a bovinocultura leiteira tem papel de destaque. Esta atividade apesar de tímida, já é uma realidade em países desenvolvidos e começa a despertar o interesse de profissionais da área no Brasil. Resultados da pesquisa de Rodrigues et al. (2005) revelaram que entre 180 produtores participantes de um programa de qualidade do leite nos EUA, apenas $24 \%$ consultavam o veterinário responsável pelo rebanho durante o planejamento de programas de qualidade do leite. Por outro lado, Rodrigues \& Ruegg (2004) constataram que a maioria dos veterinários dispendia menos que $10 \%$ de seu tempo de atividade profissional trabalhando para melhorar a qualidade do leite. Mundialmente, os resultados de pesquisas mostram os efeitos negativos das mastites, considerando-se que há motivos econômicos e sociais que justificam que o médico veterinário deve dedicar mais seu tempo nesta área (Costa et al. 1999, Fetrow 2000). As afirmações de Barker et al. (1998), Schrick et al. (2001) e de Santos et al. (2004) com relação à redução da eficiência reprodutiva tanto na mastite subclínica como clínica reforça a importância deste profissional nos programas de sanidade da glândula mamária para o controle de mastites e consequentemente para a melhor qualidade do leite.

\section{SITUAÇÃO ATUAL E PERSPECTIVAS PARA O CONTROLE}

Temos experimentado graças a Instrução Normativa IN51 (Brasil 2002) e de IN-62 (Brasil 2011), do Ministério da Agricultura, melhoria na qualidade do leite, entretanto, há ainda muito por fazer para se atingir os limites estabelecidos na IN-62 que veio para substituir a IN-51. Buscando-se a eficiência técnica e da produtividade ocorreu um aumento da produção de leite e derivados lácteos em geral. Houve também um aumento no consumo per capita (Martins 2012), mais ainda abaixo do recomendado pela Organização Mundial da Saúde.

Além da intervenção do veterinário deve haver o comprometimento do proprietário e a participação efetiva principalmente do pessoal da ordenha para que a implantação de um programa de controle possa lograr êxito. Para tanto o pessoal deve estar qualificado tecnicamente para o seu desenvolvimento. As ações de educação sanitária são importantes, devendo ser de responsabilidade do veterinário, que tem condições de ensinar as praticas corretas visando diminuir a presença de novas infecções intramamárias e a eliminação das existentes. Langoni et al. (1984) com a utilização de um plano de controle de mastites durante três anos, em duas propriedades leiteiras de alta produção, baseado principalmente na desinfecção dos tetos antes e após a ordenha, tratamento de todos os casos clínicos imediatamente após a detecção, e profilaxia à secagem com introdução de um tubo de antimastítico/teto, aliado ao controle periódico dos parâmetros pulso e pressão, e higienização de ordenhadeiras, retirada manual de fezes e lavagem do piso dos estábulos, além de aspectos de educação sanitária para os ordenhadores, obtiveram redução na ocorrência de mastites em uma propriedade de $38,09 \%$ para $2,7 \%$ e na outra de $21,0 \%$ para $3,1 \%$ ao final do estudo.

Resultados de avaliações da qualidade do leite no Brasil mostram que entre 20 a $50 \%$ dos produtores não atendem às exigências mínimas em relação à contagem bacteriana total (CBT), que no momento é de $600.000 \mathrm{UFC} / \mathrm{mL}$ de leite, para as regiões Sul, Sudeste e Centro-Oeste (Santos 2012). Se os produtores são conscientes e estimulam os ordenhadores a adotarem práticas para obtenção higiênica do leite, utilizando-se ações básicas de higiene no processo de ordenha, seguramente haverá redução na CBT tanto em propriedades com sistema de ordenha manual como mecânica, bem como diminuição de novas infecções intramamárias, que também estão relacionadas com o grau de contaminação dos tetos (Manzi et al. 2012). A redução da carga microbiana na superfície dos tetos é determinante na redução da taxa de novas infecções intramamárias (Galton et al. 1986) e consequentemente da Contagem de Células Somáticas (CCS), que se relaciona com a ocorrência de mastites subclínicas (Langoni et al. 2011).

Relacionado ainda à qualidade do leite, está sua refrigeração eficiente imediatamente após a ordenha (Celestino et al. 1996), e o primeiro desafio é a sua manutenção em temperatura inferior a $4^{\circ} \mathrm{C}$, o que de acordo com a IN-62 não deve ultrapassar três horas pós-ordenha (Brasil 2011). A temperatura de $4^{\circ} \mathrm{C}$ inibe a multiplicação bacteriana e o número de micro-organismos permanece estável por até 48 horas, havendo após proliferação de bactérias que alteram características do leite, influenciando a qualidade da matéria-prima a ser processada pela indústria, prejudicando consequentemente a qualidade dos produtos lácteos nos laticínios (Brito \& Portugal 2003).

$\mathrm{Na}$ etiologia das mastites há os micro-organismos contagiosos e os ambientais. Os principais agentes contagiosos são Staphylococcus aureus e Streptococcus agalactie e entre os ambientais, Escherichia coli, Klebsiella pnumoniae entre outros (Langoni et al. 1998). A prevalência dos patógenos contagiosos diminui consideravelmente com a adoção das medidas elencadas anteriormente (Makovec \& Ruegg 2003). Há também diminuição da ocorrência de patógenos ambientais, entretanto, neste caso deve haver intervenção no entorno onde os animais são mantidos e criados, como piso de estábulos e da cama do free stall onde os animais são mantidos e evitar que as vacas se deitem logo após a saída da sala de ordenha, momento em que o esfíncter do teto está dilatado e permite a penetração de micro-organismos 
presentes no solo contaminado (Domingues \& Langoni, 2001).

\section{ASPECTOS A SEREM CONSIDERADOS NO MONITORAMENTO}

Inicialmente deve-se considerar que a mastite é uma doença multifatorial e os elementos da tríade epidemiológica: agente - hospedeiro - meio ambiente estão interligados de forma muito clara e direta, e cada um deles apresentam características próprias e variadas, o que de pronto pode dificultar a exequibilidade e eficiência do programa de monitoramento da qualidade do leite a ser desenvolvido. Como ponto importante há o ser humano, que deve também ser colocado no centro desta cadeia, pois é ele quem cuidará dos animais, da ordenha, enfim de todo o processo de obtenção do leite. Não podemos deixar de colocar a sua satisfação e auto-estima para se comprometer com a execução do programa, e isto significa melhor remuneração pelo trabalho, e consequente valorização profissional. 0 seu engajamento será tanto melhor, quanto maior for a sua valorização como figurante importante, na preparação dos animais e da ordenha propriamente dita. Tem que haver a valorização dos recursos humanos dentro do processo produtivo de qualquer atividade e na empresa rural não deve ser diferente.

Quanto ao agente, os de origem bacteriana são os mais frequentes como Staphylococcus aureus, Streptococcus agalactie, Trüperella pyogenes, Mycoplasma spp., que são considerados contagiosos. Dentro deste grupo há ainda outros, considerados como patógenos menores como Staphylococcus coagulase negativos e Corynebacterium bovis, que de acordo com a literatura há autores que o consideram como de menor importância (Pankey et al. 1985, Bexiga et al. 2011) e outros contrariamente, como patógenos relevantes (Costa et al. 1986, Langoni et al. 1998) nas mastites.

A pluralidade etiológica é bem conhecida nas mastites. De acordo com Watts (1988) há 137 micro-organismos envolvidos nas mastites, incluindo bactérias, algas, fungos e também vírus. Há relatos do envolvimento de patógenos, variando a prevalência destes, o que pode estar relacionado com características próprias de cada propriedade bem como o manejo dos animais. Em propriedades fechadas, com o controle de entrada de novos animais é possível controlar principalmente a entrada de patógenos contagiosos, pois em muitos casos os animais podem ser fontes de infecção para outros animais na medida em que podem eliminar tais micro-organismos pelo leite, contaminando teteiras e ordenhadeiras e as mãos dos ordenhadores que disseminam para outros animais.

Com relação ao hospedeiro há vários aspectos que devem ser considerados como principalmente a idade e período de lactação. Sabidamente com a relação à idade tem-se que vacas mais velhas são mais susceptíveis pelo relaxamento natural de esfíncteres dos tetos, entretanto, a ocorrência de mastites em novilhas tem sido uma preocupação constante e cada vez mais frequente em muitas propriedades. Muitas vezes novilhas de primeira cria já parem com mastites e não raramente perdem o teto pela gravidade da infecção (Costa et al. 1996, Fox 2009). Tanto no início como no final da lactação os riscos de infecção são variáveis, considerando-se a mastite fisiológica com inflamação e edema do úbere, com posterior infecção uma vez que o micro-organismo pode estar presente na glândula mamária sob forma de mastite subclínica e evoluir para clínica, pela predisposição e injúria ao tecido mamário (Pipers et al. 2009). Ao final da lactação tal fato também pode acontecer pelas ordenhas serem mais espaçadas e possibilidade de leite residual o que favorece como fator condicionante o desenvolvimento microbiano, funcionando assim como meio de cultura. Desta forma justifica-se a profilaxia de mastites na secagem, último dia de lactação utilizando-se formulação específica para secagem, com permanência do princípio medicamentoso por período maior de tempo na glândula mamária (Green et al. 2002). Tal prática consiste no tratamento de mastites subclínicas à secagem ou profilática no caso dos tetos não infectados (Bradley \& Green 2001, Berry \& Hillerton 2002).

As características próprias do hospedeiro como os aspectos sanitários, nutricionais e de imunidade influenciam também na ocorrência de mastites e devem ser priorizadas. Dieta equilibrada suplementada de vitaminas e sais minerais, principalmente vitamina $E$ e selênio são importantes para melhorar as defesas orgânicas e tem-se mostrado importantes no controle não somente das mastites (Hogan et al. 1993), mas também de outros processos infecciosos.

0 meio ambiente desempenha papel fundamental na profilaxia e controle de qualquer enfermidade infecciosa. Características, por exemplo, como temperatura, umidade, tipo e $\mathrm{pH}$ do solo podem ser fatores de risco e dificultar programas de controle, independente da doença em questão (West, 2003). Desta forma os aspectos ambientais devem ser considerados de forma a permitir êxito no controle, neste caso especificamente as mastites. Podemos dizer que o bem estar animal está diretamente relacionado ao meio ambiente, principalmente no que diz respeito ao conforto térmico do animal, importante para a produção leiteira nos trópicos (Shaerer \& Bray 1995, Kadzere et al. 2002).

Objetivando-se ainda o controle de mastites e da qualidade do leite, além da vaca e do meio ambiente, como comentado anteriormente, há que se pensar nos recursos humanos para manejar as vacas e os equipamentos de ordenha, que contribuem para a exposição aos patógenos das mastites, especialmente os contagiosos, mas também dos ambientais, com a transmissibilidade de micro-organismos de uma vaca para outra durante a ordenha.

Associado a esses aspectos, deve-se lembrar de tema importante que é a sustentabilidade da produção o que somente pode ser obtido com práticas adequadas no sistema de produção da cadeia produtiva do leite. Atualmente não se pode pensar em processo produtivo ou cadeia produtiva de determinado alimento sem considerar os aspectos de bem estar animal e de sustentabilidade da produção e do meio ambiente, já na fase de projeto e planejamento da produção pretendida. Enfatiza-se que o meio ambiente, resíduos químicos e cuidados com o bem-estar animal começam a entrar na ordem do dia do produtor brasileiro, e que de maneira geral o nível de exigência sobre o produtor é crescente, e para continuar na atividade será necessário 
associar a eficiência técnica a econômica, independente do tamanho da produção, sendo importante ainda, encarar o leite realmente como negócio.

\section{VIGILÂNCIA EPIDEMIOLÓGICA NAS MASTITES}

A detecção de casos de mastite é fundamental, e é necessário que tanto produtor quanto ordenhadores definam corretamente o que é a mastite, que se caracteriza por alterações nas características do leite como cor, produção de grumos, pus e sangue, nos casos clínicos, e o leite normal em casos subclínicos, entretanto, com aumento de CCS/ $\mathrm{mL}$ de leite, diagnosticada pela contagem eletrônica ou visualmente pelo exame do California Mastitis Test (CMT) que mostra alterações na viscosidade do leite frente à ação do reagente púrpura de bromocresol. Os escores são variáveis de negativo a três cruzes, de acordo com Schalm e Noorlander (1956), em função da intensidade da resposta inflamatória. Além do diagnóstico correto, é necessário o seu registro, o que permite avaliar o histórico da vaca para decisões futuras. Nas mastites clínicas é importante a avaliação (Wenz et al. 2001), baseando-se nos sinais clínicos como grau 1, quando há somente alterações no leite, grau 2 , alterações no leite e úbere endurecido e grau 3, quando a vaca apresenta também sintomas gerais. Deve-se entender que a gravidade de cada caso associa-se ao prognóstico para a cura e ao período de tempo transcorrido entre o diagnóstico e o tratamento, insistindo-se na prática do diagnóstico precoce, com a observação dos primeiros jatos de leite antes de cada ordenha (caneca de fundo negro ou prova de Tamis).

0 registro dos casos clínicos, com anotação de suas características oferece ao veterinário perspectivas de probabilidade de êxito no tratamento e avaliação de características epidemiológicas (Wenz 2004). Assim sendo deve-se conhecer: a incidência de mastite clínica, ou seja, a taxa de casos novos, a taxa de casos graves (grau 3), o micro-organismo de maior ocorrência, os protocolos de tratamento, dias de descarte do leite em função do tratamento. Ainda é relevante conhecer o número de casos com alteração no protocolo estabelecido para o tratamento, se apresentam recidivas na mesma lactação, o número (\%) de vacas ordenhadas com menos de quatro tetos e o número (\%) de vacas com mastite clínica descartadas, ou que morreram devido a mastite. Os registros diários de ocorrência podem ser realizados em fichas para rebanhos menores ou computadorizados nos maiores, o que permite nesse caso uma análise mais rápida (Rhoda 2007) e deve ser definido para cada animal em lactação (Wenz 2004).

De maneira prática estabelece-se como casos novos de mastite, aqueles que ocorrem em intervalo de 14 a 21 dias, entre um e outro, e pode ser adaptado de acordo com as características da propriedade. Neste contexto são estabelecidos indicadores chaves de desempenho (ICD), definidos por animal com mastite clínica em um ou mais tetos. Com relação à incidência sugere-se a meta de menos que 25 casos por100vacas/ano, 2-3 casos por 100vacas/mês, 5 a $20 \%$ do total de casos com escore 3 e $2 \%$ de animais que morrem por mastite, menos de $20 \%$ de casos com mudança no tratamento, menos que $30 \%$ de casos recidivantes, e menos que $20 \%$ de vacas com mastites em mais de um teto. Quanto ao número de dias de descarte do leite deve ser de 4-6 dias, em função do número de dias de tratamento, podendo ser maior quando o tratamento for por 6 dias (tratamento estendido no caso de Staphylococcus aureus) e a porcentagem de vacas com menos de quatro tetos ordenhados deve ser inferior a $5 \%$.

No caso de mastites subclínicas, para o seu monitoramento é necessário a interpretação de variáveis epidemiológicas como a sua prevalência, o que quer dizer o número de casos novos e antigos no período e a sua incidência, que significa o número de casos novos no período. Os micro-organismos contagiosos via de regra ocasionam infecções crônicas e os ambientais, infecções de curta duração e agudas. Para monitorar a ocorrência pode-se utilizar uma ferramenta simples como o CMT mensalmente, entretanto a CCS individual de amostra composta de cada vaca em lactação, bem como do tanque de expansão é a melhor forma para o monitoramento, já que há correlação entre CCS e ocorrência de mastite subclínica (Pantoja et al. 2009). Vacas com CCS superiores a 200.000, o que significa um escore linear ao redor de 4.0, são consideradas como mastite subclínica.

Devem ser avaliados os seguintes tópicos: qual a prevalência e a incidência desse tipo de mastite baseando-se na CCS, ou se não for possível, pelo CMT; qual o micro-organismo mais isolado em vacas com CCS superior a 200.000 $\mathrm{CCS} / \mathrm{mL}$ de leite; qual a porcentagem de casos subclínicos que se tornaram crônicos, ou seja, persistentes em dois meses (duas análises consecutivas); qual a prevalência por dias e ordem de lactação; qual a porcentagem de vacas com mastite no primeiro teste de lactação e no último. Esses dados devem ser encontrados nas planilhas do laboratório da Rede Brasileira de Qualidade do Leite (RBQL) responsável pelas análises, ou ainda a partir da utilização de softwares de gerenciamento. Como indicadores chave de desempenho, considera-se que $85 \%$ das vacas (prevalência) com CCS/mL de leite menor que 200.000 e menos de $5 \%$ das vacas com mastite subclínica no mês (incidência).

O monitoramento do padrão mensal de CCS para cada animal ou do rebanho, orienta para o diagnóstico e resolução da situação. Quando o rebanho ultrapassa a meta estabelecida para a prevalência de mastite subclínica no primeiro teste, pode tratar-se de mastites ambientais. Desta forma devem ser investigadas as condições de alojamento (free stall), processo de higiene e desinfecção do úbere e o manejo de vacas secas e no periparto. Quando a mastite é contagiosa, a prevalência da mastite subclínica aumenta com o período de lactação e com a idade das vacas, pelas maiores chances de exposição aos patógenos. Neste caso a transmissão deve estar ocorrendo durante a ordenha e os responsáveis podem ser pré-dipping inadequado ou utilização de fômites contaminados como toalhas de secagem dos tetos, que devem ser devidamente higienizadas e individuais para cada vaca (de pano ou papel). Para facilitar a interpretação, um número grande de vacas com aumento de CCS em mais de dois exames mensais consecutivos, significa que as vacas estão infectadas com patógenos adaptados ao animal, ou seja, contagiosos. O CMT ou CCS de cada 
teto orientam condutas como a segregação do animal. 0 exame microbiológico de amostra de leite e o tratamento ou descarte depende do histórico do animal, como nos casos de vacas repetidoras de mastite por $S$. aureus.

\section{CONTROLE DE QUALIDADE PELO TANQUE DE EXPANSÃO}

Podem ser utilizadas tanto a CCS como a UFC/mL de leite para o monitoramento da qualidade do leite, e pagamento de bônus com base principalmente na qualidade microbiológica do leite. A contaminação do leite pode ocorrer durante a ordenha se a limpeza e higienização não forem adequadas, podendo veicular os micro-organismos ambientais, como os coliformes bem como os oriundos da ordenha e, portanto, patógenos de mastites (Reinemann et al. 1999). O leite de úberes sadios tem $<1.000 U F C / m L$ e não influencia significativamente para a contagem de micro-organismos no tanque, exceto se houver grande quantidade de determinado patógeno; ou para o aumento do número destes durante a refrigeração de acordo com Murphy e Boor (2000). Como padrões de qualidade podem ser realizadas, a contagem padrão em placa, a contagem do leite pasteurizado que é realizada com leite aquecido a $62.8^{\circ} \mathrm{C}$ por 30 minutos (baixa temperatura por tempo prolongado), pois identifica aqueles micro-organismos que sobrevivem à pasteurização, considerados termodúricos, como Micrococcus spp., Lactobacillus spp., Bacillus spp., Clostridium spp. e algumas espécies de estreptococos. Os patógenos que causam mastites, não resistem à pasteurização. Pode ser realizada ainda contagem de coliformes (Escherichia coli e Klebsiella spp.) que se relacionam principalmente com a higienização durante o processo de ordenha. Segundo Reinemann et al. (1999) a contagem no leite pasteurizado deve estar entre 100 e $200 \mathrm{UFC} / \mathrm{mL}$, sendo que um resultado inferior a $10 \mathrm{UFC} / \mathrm{mL}$ indica excelente higiene do equipamento. Aumento na contagem de leite pasteurizado pode estar associado ao desenvolvimento de biofilmes em equipamentos de ordenha mal higienizados.

\section{O EXAME MICROBIOLÓGICO DO LEITE}

0 ideal é o exame microbiológico de amostra composta de leite de cada animal em meios padrões como o ágar base, adicionado de 5-8\% de sangue ovino ou bovino e ágar MacConckey, o que permite a caracterização dos patógenos mais importantes das mastites sejam elas contagiosas ou ambientais. Paralelamente deve-se cultivar amostra obtida do tanque de expansão pelo método de diluições sucessivas possibilitando a contagem microbiana, além da avaliação da presença de $S$. aureus. Deve-se incluir ainda a pesquisa de Mycoplasma spp., que requer meios de cultura especiais para seu isolamento (Pretto et al. 2001). Deve-se ter cuidado com a coleta e armazenamento da amostra em frasco estéril mantido sob refrigeração para encaminhamento ao laboratório.

Podem estar sendo isolados patógenos de mastites subclínicas ou de casos clínicos que são ordenhados juntamente e ainda contaminantes, mas a associação do resultado da CCS do tanque pode auxiliar na interpretação dos resultados, pois no caso de contaminação, a CCS tende a estar dentro dos limites de normalidade (Langoni et al. 2011). Mesmo com essas limitações é útil para caracterizar rebanhos com mastites contagiosas por Staphylococcus aureus, Streptococcus agalactiae e Mycoplasma spp. Há uma boa relação de encontro destes e a ocorrência de mastites (Wilson \& Gonzales 1997), entretanto, a sensibilidade do exame não é alta o suficiente para garantir que não há determinado patógeno no rebanho, pois deve-se considerar a sua eliminação intermitente e a quantidade eliminada pelo leite. A sensibilidade pode melhorar com o exame de quatro amostras obtidas em dias consecutivos (Farnsworth 1993), que podem ser mantidas sob refrigeração e encaminhadas ao laboratório. Pode-se proceder contagens individuais ou obter amostra única, composta dos quatro tetos, tornando o exame mais barato.

\section{A ORDENHA COMO PONTO CRUCIAL NAS MASTITES}

A higienização dos copos da ordenhadeira e a sua adaptação aos tetos é fundamental para a produção de leite de qualidade sendo essencial conhecer o funcionamento da ordenhadeira e a supervisão periódica por técnico especializado para avaliar fluxo de ar, pulsação, nível de vácuo e outros aspectos da ordenha (Reinemann et al. 2003). Como indicadores chaves do desempenho estão: vácuo médio (35-42 kPa) e a flutuação máxima do vácuo no copo coletor $(<10 \mathrm{kPa})$. Os pulsadores devem estar adequados para garantirem a duração adequada da fase de massagem do ciclo de pulsação. 0 manejo adequado do processo de ordenha é ponto chave para controle de mastites (Hamann 1990, Mein et al. 2004). Durante a ordenha deve-se atentar para:

- Todo o processo de ordenha deve ser realizado com a utilização de luvas descartáveis de látex, diminuindo a disseminação de patógenos da mastite pelas mãos contaminadas dos ordenhadores.

- Limpeza e desinfecção dos tetos. A conduta é variável de acordo com o grau de sujidade do úbere e tetos. Se os tetos estiverem limpos não há necessidade de lavá-los. Se o grau de sujidade for grande, deve-se proceder lavagem somente dos tetos, previamente à imersão em solução desinfetante antes da ordenha. Segundo Galton et al. (1986) a imersão dos tetos em solução de iodo reduz 5 e 6 vezes a contagem padrão em placas e contagem de coliformes, respectivamente. A técnica de pré-dipping reduz o isolamento de Listeria monocytogenes de filtros de leite, ao redor de 4 vezes de acordo com Hassan et al. (2001). Para redução efetiva de micro-organismos deve-se garantir um tempo de permanência do produto em contato com a pele limpa, no mínimo por 30 segundos.

-Exame dos primeiros jatos de leite antes da ordenha. Esta prática permite o diagnóstico precoce das mastites clínicas, indicando o seu início pela formação de grumos ou coágulos de pus, além de evitar a entrada de leite alterado, no tanque da propriedade. 0 ato de desprezar os primeiros (2-3) jatos de leite aumenta a segurança e ainda auxilia na descida do leite. Não observou-se diferença na qualidade do leite, quanto a ordem em que se realiza o pré-dipping e descarte dos primeiros jatos (Rodrigues et al. 2005) 
- Secagem dos tetos. É uma fase importante e garante a higienização do úbere. Devem ser utilizadas toalhas de papel descartável e atualmente já há toalhas de pano esterilizadas para uso individual. Galton et al. (1986) demonstraram que a secagem dos tetos reduz a contagem de bactérias nas pontas dos tetos de 35.000 a $40.000 \mathrm{UFC} / \mathrm{mL}$ para tetas limpas não secas e para 11.000-14.000 UFC/mL naquelas também secas com toalha de papel descartável. A importância da utilização de toalhas de papel ou de pano seco foi enfatizada por Rodrigues et al. (2005) que observaram uma taxa mensal de mastite clínica de 7,8\% nos rebanhos com utilização de uma toalha/vaca, contra $12,3 \%$ naqueles que usavam uma toalha para mais de uma vaca.

- Início da ordenha propriamente dita. As vacas devem estar bem estimuladas, mostrando a descida do leite antes da colocação da ordenhadeira. 0 intervalo entre a estimulação da vaca e colocação da ordenhadeira denomina-se "pré-lag-time" ou período de estimulação, que é variável com o nível de produção, fase de lactação, intervalo entre as ordenhas e raça (Bruckmaier 2005). Há indicação do período de 45-90 segundos (Dzidic et al. 2004, Maroney et al. 2004) para a colocação da unidade de ordenha na vaca.

- Manejo da vaca pós ordenha. A utilização do pós-dipping foi previsto inicialmente para resolução das mastites contagiosas, destruindo bactérias aderidas à pele após a ordenha, por outro lado, mantêm proteção do óstio do teto contra a invasão de patógenos ambientais, pois com a ordenha o esfíncter do teto está relaxado favorecendo a penetração de micro-organismos. É preciso garantir que este processo seja efetivo, com soluções equilibradas, e que contenham corante para facilitar a visualização do produto e o grau de cobertura do teto, insistindo-se para que o produto tenha ação por todo o teto do animal. Deve-se propiciar que a vaca fique o maior tempo possível em pé, após a saída da sala de ordenha. Para tanto deve-se oferecer alimento em cocho a parte, o que faz como que a vaca fique em pé por 1-2 horas, quando o esfíncter já voltou ao normal. Esta medida tem reduzido a ocorrência de mastites. Há ainda a indicação da utilização de selantes de tetos que propiciam a formação de uma película protetora do óstio do teto, impedindo a penetração de patógenos logo após a ordenha, protegendo da invasão bacteriana por um período de tempo maior, até a ordenha seguinte (Santos \& Fonseca 2007).

\section{CONSIDERAÇÕES FINAIS}

Acredita-se na possibilidade de produtos lácteos de melhor qualidade, entretanto é preciso que todos os envolvidos na cadeia produtiva do leite se conscientizem do seu papel para que isto aconteça. Produtores, ordenhadores, a indústria de laticínios e técnicos envolvidos na produção leiteira tem um papel importante e seguramente estarão garantindo o bem estar animal, uma melhor qualidade do leite produzido, maior lucratividade para o produtor e laticinistas e a sustentabilidade da produção. Resumidamente a qualidade do leite depende de todos, incluindo-se tam- bém os consumidores, elementos finais da cadeia produtiva do leite.

\section{REFERÊNCIAS}

Barker A.R., Schrick F.N., Lewis M.J., Dowlen H.H. \& Oliver S.P. 1998. Influence of clinical mastitis during early lactation on reproductive performance of Jersey cows. J. Dairy Sci. 81:1285-1290.

Berry E.A. \& Hillerton J.E. 2002. The effect of selective dry cow treatment on new intramammary infections. J. Dairy Sci. 85:112-121.

Bexiga R., Koskinen M.T., Holopainen J., Carneiro C., Pereira H., Ellis K.A. \& Vilela CL. 2011. Diagnosis of intramammary infection in samples yielding negative results or minor pathogens in conventional bacterial culturing. J. Dairy Res. 78:49-55.

Bradley A.J. \& Green M.J. 2001. An invstigation of the impact of intramammary antibiotic dry cow therapy on clinical coliform mastitis. J. Dairy Sci. 84:1632-1639.

Brasil 2002. Regulamento técnico de produção, identidade e qualidade do leite tipo A, do leite tipo B, do leite tipo $\mathrm{C}$, do leite pasteurizado e do leite cru refrigerado e o regulamento técnico da coleta de leite cru refrigerado e seu transporte a granel. Instrução Normativa no 51, de 18 de setembro de 2002. Diário Oficial da União, 18 de setembro de 2002, Ministério da Agricultura, Pecuária e Abastecimento, Brasília, DF.

Brasil 2011. Regulamento técnico de produção, identidade e qualidade do leite tipo $\mathrm{A}$, o regulamento técnico de identidade e qualidade de leite cru refrigerado, o regulamento técnico de identidade e qualidade de leite pasteurizado e o regulamento técnico da coleta de leite cru refrigerado e seu transporte a granel. Instrução Normativa no 62, de 29 de dezembro de 2011. Diário Oficial da União, 29 de dezembro de 2011, Ministério da Agricultura, Pecuária e Abastecimento, Brasília, DF.

Brito J.R.F. \& Portugal J.A.B. 2003. Diagnóstico da Qualidade do Leite, Impacto para a Indústria e a Questão de Resíduos de Antibióticos. Embrapa Gado de Leite - Epamig/CT/ILCTn, Juiz de Fora, MG. 168p.

Bruckmaier R.M. 2005. Normal and disturbed milk ejection in dairy cows. Domestic Anim. Endo. 29:268-273.

Celestino E.L., Iyer M. \& Roginski H. 1996. The effects of refrigerated storage on the quality of raw milk. Aust. J. Dairy Technol. 51:59-63.

Cerqueira M.M.O.P. \& Leite M.O. 1995. Doenças transmissíveis pelo leite e derivados. Cad. Téc. Esc. Vet. UFMG 13:39-65.

Costa E.O., Coutinho S.D., Castilho W. \& Teixeira C.M. 1986. Etiologia bacteriana da mastite bovina no Estado de São Paulo, Brasil. Vet. Microbiol. 17:107-112.

Costa E.O., Melville P.A., Ribeiro A.R., Watanabe E., Viane F.V. \& White C.R. 1996. Prevalence of intramammary infection on primigravidis brazilian dairy heifers. Prev. Vet. Med. 29: 151-155.

Costa E.O., Ribeiro A.R., Watanabe E.T., Silva J.A.B., Garino Jr F., Benites N.R. \& Horiuti A.M. 1999. Mastite subclínica: prejuízos causados e custos de prevenção em propriedades leiteiras. Revta Napgama 2:16-29.

De Buyser M.L., Dofur B., Maire M. \& Lafarge V. 2001. Implication of milk and milk products in food-borne diseases in France and in different industrialized countries. Int. J. Food Microbiol. 67:1-17.

Domingues P.F., Langoni H. \& Padovani C.R. 1998. Influência da mastite bovina subclínica sob a produção de leite. Vet. Zootec. 10:99-106.

Domingues P.F., Langoni H. 2001. Manejo Sanitário Animal. Editora de Publicações Biomédicas. Ltda - EPUB, Rio de Janeiro. 209p.

Dzidic A., Macuhova J. \& Bruckmaier R.M. 1991. Effects of cleaning duration and water temperature on oxytocin release and milk removal in an automatic milking system. J. Dairy Sci. 87:4163-4169.

Fagundes H. \& Oliveira C.A.F. 2004. Infecções intramamárias por Staphylococcus aureus e suas implicações em saúde pública. Ciência Rural 34:1315-1320.

Farnsworth R.J. 1993. Microbiologic examination of bulk tank milk. Vet. Clin. North Am. Food Anim. Pract. 9:469-474.

Fetrow J. 2000. Mastitis: an economic consideration. Proc. $39^{\text {th }}$ Annual Conference National Mastitis Council, Atlanta, GA, p.3-47. 
Fetrow J., Mann D., Butcher K. \& McDaniel B. 1991. Production losses from mastitis: carry-over the preceding lactation. J. Dairy Sci. 74:833-839.

Fox L.K. 2009. Prevalence, incidence and risk factors of heifer mastitis. Vet. Microbiol. 134:82-88.

Galton D.M., Peterson L.G. \& Merrill W.G. 1986. Effects of premilking udder preparation practices on bacterial counts in milk and on teats. J. Dairy Sci. 69:260-266.

Green M.J., Green L.E., Medley G.F., Schukken Y.H. \& Bradley A.J. 2002. Influence of dry period bacterial intra-mammary infection of clinical mastitis in dairy cows. J. Dairy Sci. 85:2589-2599.

Guimarães F.F. \& Langoni H. 2009. Leite: alimento imprescindível, mas com riscos para a saúde pública. Vet. Zootec. 16:38-51.

Hamman J. 1990. Milking hygiene, milking and mastitis. International Symposium on Bovine Mastitis, Indianapolis, IN, p.210-220.

Hassan L., Mohammed H.O. \& McDonough P.L. 2001. Farm-management and milking practices associated with the presence of Listeria monocytogenes in New York state dairy herds. Prev. Vet. Med. 51:63-73.

Hogan J.S., Weiss W.P. \& Smith K.L. 1993. Role of vitamin-e and selenium in host-defense against mastitis. J Dairy Sci. 76:2795-2803.

Kadzere C.T., Murphy M.R., Silanikove N. \& Maltz E. 2002. Heat stress in lactating dairy cows: a review. Livest. Prod. Sci. 77:59-91.

Langoni H., Corrêa C.N.M., Corrêa W.M. \& Carreira E.L.C. 1984. Etiologia e tratamento das mastites bovinas com auxílio do dimetilsulfóxido (DMSO). Pesq. Vet. Bras. 4:1-4.

Langoni H., Penachio D.S., Citadella J.C.C., Laurino F., Faccioli-Martins P.Y., Lucheis S.B., Menozzi B.D. \& Silva A.V. 2011. Aspectos microbiológicos e de qualidade do leite bovino. Pesq. Vet. Bras. 31:1059-1065.

Langoni H., Silva A.V., Cabral K.G. \& Domingues P.F. 1998. Aspectos etiológicos na mastite bovina: flora bacteriana aeróbica. Revta Bras. Med. Vet. 20:204-209.

Lescourret F. \& Coulon J.B. 1994. Modeling the impact of mastitis on milk-production by dairy-cows. J. Dairy Sci. 77:2289-2301.

Makovec J.A. \& Ruegg P.L. 2003. Characteristics of milk samples submitted for microbiological examination in Wisconsin from 1994 to 2001. J. Dairy Sci. 86:3466-3472.

Manzi M.P., Facciolli P.Y., Nobrega D.B., Troncarelli M.Z. \& Langoni H. 2012. Relationship between teat-end condition, udder cleanliness and bovine subclinical mastitis. Res. Vet. Sci. 93:430-434.

Maroney M., Ruegg P.L., Tayar F. \& Reinemann D.J. 2004. Use of Lactocorder $^{\mathrm{TM}}$ to evaluate milking routines. Proc $43^{\text {rd }}$ Annual Meeting of the National Mastitis Council. Charlotte, NC, p.341-342.

Martins P.C. 2012. Profissionalização do produtor e maturidade na indústria. Mundo do Leite 54:8-10.

Mein G., Reinemann D., Schuring N. \& Ohnstad I. 2004. Milking machines and mastitis risk: a storm in a teatcup. Proc. Annual Meeting of the National Mastitis Council, Charlotte, NC, p.176-188.

Miller G.Y., Bartlett P.C., Lance S.E., Anderson J. \& Heider L.E. 1993. Cost of clinical mastitis and mastitis prevention in dairy herds. J. Am. Vet. Med. Assoc. 202:1230-1236.

Murphy S.C. \& Boor K.J. 2000. Trouble-shooting sources and causes of high bacteria counts in raw milk. Dairy Food Environ. Sanit. 20:606-611.

Oliver S.P., Jayarao B.M. \& Almeida R.A. 2005. Food borne pathogens, mastitis, milk quality and dairy food safety. Proc. Annual Meeting of the National Mastitis Council, Charlotte, NC, p.3-217.

Pankey J.W., Nickerson S.C., Boddie R.L. \& Hogan J.S. 1985. Effects of Cory- nebacterium bovis infection on susceptibility to major mastitis pathogens. J. Dairy Sci. 68:2684-2693.

Pantoja J.C.F., Reinemann D.J. \& Ruegg P.L. 2009. Association between bacterial and somatic cell counts in raw bulk milk. J. Dairy Sci. 92:49784987.

Pipers S., Vliegher S., Kruif A., Opsomer G. \& Barkema H.W. 2009. Impact of intramammary infections in dairyheifers on futureudder health, milk production and culling. Vet. Microbiol. 134:113-120.

Pretto L.G., Muller E.E., Freitas J.C., Mettifogo E., Buzinhani M., Yamaguti M. \& Salvador R. 2001. Bovine mastitis in dairy cows caused by Mycoplasma bovis. Pesq. Vet. Bras. 21:143-145.

Reinemann D.J., Mein G.A., Bray D.R., Reid D. \& Britt J.S. 1999. Troubleshooting high bacteria counts in farm milk. Univ. Wisconsin Coop. Ext. Publ. A3705, Madison, WI.

Reinemann D.J., Wolters G.M.V.H., Billon P., Lind O. \& Rasmussen M.D. 2003. Review of practices for cleaning and sanitation of milking machines. Bull. IDF 381:4-18.

Rhoda D.A. 2007. Evaluating mastitis records. In Proceeding. CVC West., San Diego, CA, p.971-973.

Rodrigues A.C.O., Caraviello D.Z. \& Ruegg P.L. 2005. Management of Wisconsin dairy herds enrolled in milk quality teams. J. Dairy Sci. 88:26602671.

Rodrigues A.C.O. \& Ruegg P.L. 2004. Opinions of Winsconsin dairy professionals about milk quality. Food Protection Trends 24:1-6.

Santos J.E., Cerri R.L., Ballou M.A., Higgingbotham G.E. \& Kirk J.H. 2004. Effect of timing of first clinical mastitis occurrence on lactation and reproductive performance of Holstein dairy cows. Anim. Reprod. Sci. 80:31-45.

Santos M.V. 2012. Cuidados com higiene melhoram contagem bacteriana total. Mundo do Leite 55:13-16.

Santos M.V. \& Fonseca L.F. 2007. Estratégia para Controle de Mastite e Melhoria na Qualidade do Leite. Editora Manole, São Paulo. 314p.

Schalm O.W. \& Noorlander D.O. 1956. California Mastitis Test. Calif. Vet. 9:33.

Schrick F.N., Hockett M.E., Saxton A.M., Lewis M.J., Dowlen H.H. \& Oliver S.P. 2001. Influence of subclinical mastitis during early lactation and reproductive parameters. J. Dairy Sci. 84:1407-1412.

Shaerer J.K. \& Bray D.R. 1995. Efeito do calor e estresse ambiental sobre a saúde da glândula mamária. Anais $2^{\circ}$ Interleite Simpósio sobre Produção Intensiva de Leite, São Paulo, SP, p.45-52.

Vasconcelos S.A. \& Ito F.H. 2011. Principais zoonoses transmitidas pelo leite: atualização. Revta Educ. Cont. CRMV-SP 9:32-37.

Watts J.L. 1988. Etiological agents of bovine mastitis. Vet. Microbiol. 16:41-59.

Wenz J.R. 2004. Practical monitoring of clinical mastitis treatment programs. Proc. $43^{\text {rd }}$ Annual Meeting of the National Mastitis Council, Charlotte, NC, p.41-46.

Wenz J.R., Barrington G.M., Garry F.B., Dinsmore R.P. \& Callan R.J. 2001. Use of systemic disease signs to assess disease severity in dairy cows with acute coliform mastitis. J. Am. Vet. Med. Assoc. 218:567-572.

West J.W. 2003. Effects of heat-stress on production in dairy cattle. J. Dairy Sci. 86:2131-2144.

Wilson D.J., Gonzalez R.N. \& Das H.H. 1997. Bovine mastitis pathogens in New York and Pennsylvania: prevalence and effects on somatic cell count and milk production. J. Dairy Sci. 80:2592-2598. 